\title{
VALIDITY AND RELIABILITY OF THE TURKISH VERSION OF THE PUBLIC HEALTH LITERACY KNOWLEDGE SCALE
}

\author{
Aykut ARDIC ${ }^{1}$, Hakan DEMIRCI ${ }^{2}$, Gokhan OCAKOGLU ${ }^{3,} \mathrm{Nazli} \mathrm{DEMIRCI}^{4}$
}

\footnotetext{
${ }^{1}$ Yenisehir \# 1 Siteler Family Health Center, Bursa, TURKEY

${ }^{2}$ Department of Family Medicine, University of Health Sciences Turkey Bursa Yuksek ihtisas Training and Research Hospital, Bursa, TURKEY

3 Department of Biostatistics, Uludag University Medical Faculty, Bursa, TURKEY

${ }^{4}$ Sociology, Bursa Technical University, Bursa, TURKEY
}

\begin{abstract}
Aim: To translate the "Public Health Literacy Knowledge Scale" questionnaire developed by Pleasant and Kuruvilla into Turkish, to investigate the validity and reliability of the Turkish questionnaire.

Methods: The necessary permissions have been obtained. The translation of the English form into Turkish was carried out in two steps. Sampling of 290 people was deemed sufficient. In evaluating the reliability of the scale (Test-retest method), the relationship between the Turkish and English forms of the scale was analyzed with correlation analysis in line with the answers received from 40 undergraduate students. The content validity of the scale was evaluated with the Newest Vital Signs scale.
\end{abstract}

Results: English and Turkish forms were found to have a high level of positive correlation in the language equivalence study of the scale. A significant relationship between the Public Health Literacy Knowledge scale and the total scale scores of the Newest Vital Sign scales has been determined in the same direction and it has been assumed that the Public Health Literacy Knowledge scale provides the validity of the criteria. When the scale reliability was examined in terms of internal consistency, the Cronbach alpha coefficient of the Public Health Literacy Knowledge scale was found to be $\alpha=0.58$. Looking at the Cronbach Alpha coefficient, it seems that this scale is a poor measurement tool in terms of internal consistency. In a reliability study by Test-retest method, the Public Health Literacy Knowledge scale was re-applied to a group of 40 people three weeks after the first application, and the test-retest correlation was found to be $r s=0.93$ ( $p<0.001$ ).

Conclusions: The Turkish validity of the Public Health Literacy Knowledge Scale was provided in this study. The internal consistency of the scale is poor, but its reliability can be evaluated as excellent.

Keywords: Public Health Literacy Knowledge Scale, Fact for Life, Newest Vital Sign, validation

Corresponding Author: Aykut ARDIC aardic.dr@gmail.com

Received: March 28, 2021; Accepted: April 5, 2021; Published Online: April 23, 2021

Cite this article as: Ardic, A., Demirci, H., Ocakoglu, G. \& Demirci, N. (2021). Validity and reliability of the Turkish version of the public health literacy knowledge scale. European Health Literacy Journal 1(1), 33-44. 


\section{Introduction}

'Facts for Life' is health research validated knowledge vetted by a range of public health professionals working in a variety of international contexts. A collaborative process among the major international organizations - UNICEF (United Nations Children's Fund), WHO (World Health Organization), UNESCO (United Nations Educational and Cultural Organization), UNFPA (United Nations Population Fund), UNDP (United Nations Development Program), UNAIDS (United Nations HIV/AIDS Joint Program), the World Trade Organization and the World Bank developed Facts for Life. 'Facts for life' is explained under fourteen topics including timing of births; safe motherhood and newborn health; child development and early learning; breastfeeding; nutrition and growth; immunization; diarrhea; coughs, colds and more serious illnesses; hygiene; malaria; HIV (Human Immunodeficiency Virus) / AIDS (Acquired Immunodeficiency Syndrome); child protection; injury prevention; emergencies: preparedness and response (1).

Pleasant and Kuruvilla developed the 'Public Health Literacy Knowledge Scale' by improving the facts for life. The scale was tested by the WHO (World Health Organization) in coordination with independent local partners in Mexico, China, Ghana and India (2). The aim of this study was to translate the Public Health Literacy Knowledge scale developed by Pleasant and Kuruvilla to Turkish and to determine its Turkish validity and reliability.

\section{Methods}

We made contact with Andrew Pleasant, the developer of the 'Public Health Literacy Knowledge Scale' for the Turkish adaptation of the scale and we obtained the necessary permission.
University of Health Sciences, Bursa Yuksek Ihtisas SUAM, Academic Committee approval was obtained (08.11.2017).

Uludağ University, Medical Faculty, Ethics Committee approval was obtained (20.02.2018).

Ministry of Health, Turkish Public Health Institution, Research and Assessment Committee approval was obtained (08.05.2018).

\section{Translation of English Form to Turkish}

In scale adaptation studies from foreign languages, conformity of expressions to the target language and culture is of great importance. Translation of the form from English to Turkish was accomplished in two stages. In the first step, the scale was translated to Turkish by two experts; a native Turkish linguist and a professional in the field by considering the scale items independently from each other. Then, it was examined by the researchers in terms of the most appropriate translation, content integrity and conceptual equivalence for each item. The scale that was translated to Turkish was re-translated to English with a back-translation method. Then it was compared with its original form and translations considered as the best expressing ones for the questionnaire items were adapted.

\section{Determination of the sample size}

Sample size is an important factor for accurate results of the estimate method in confirmatory factor analysis but there is no definite agreement on what the sample size should be (3).

According to Kline, sample size should be 10 times the number of items and not fewer than 200 (4). Andrew et al. have suggested that sample size is preferred to 
be 20 for each item but 10 for each item could be sufficient (5).

MacCallum, Widaman, Zhang and Hong and Erkuş have suggested that sample size should be at least 5 times the number of scale items $(6,7)$.

In this study, we considered the criteria suggested by Kline and 290 individuals were included in the sample group considering possible sample losses and the language equivalence study of the scale.

\section{Assessment of scale reliability (Test-retest method)}

The finalized Turkish questionnaire form was submitted to 40 undergraduate students in the Departments of English Teaching and English Language and Literature. 3 weeks later, the English questionnaire form was given to the same students.

Following the answers of 40 undergraduate students, the relationship between Turkish and English versions of the scale was examined with correlation analysis.

\section{Scale content validity}

This was assessed with the Newest Vital Sign (NVS) scale developed by Barr D. Weiss et al. (8). The Public Health Literacy Knowledge Scale (PHLS) Turkish version and the NVS scale were given to 250 individuals who had been admitted to Yenişehir No 1 Siteler FHC for examination and check-out. 40 of 250 individuals were re-given the Public Health Literacy (PHL) Scale Turkish version and NVS scale after 2 weeks.

In the data collecting process, English final year students were presented first with the Turkish form answers in one session in the classroom. After 3 weeks, the English form answers were presented to the same students in one session. A face-to-face interview method was used for patients who had visited the Yenisehir Siteler Family Health Center registered to the family medicine department.

\section{Study type and population}

\section{Participants}

This study was performed with volunteer final year students studying in Uludag University, Faculty of Education, Department of English, with 250 volunteer individuals between age 20-69, with a proportionally equal number with the unit population pyramid, registered in Family Health Department No 1617001 of Bursa Yenisehir No1 Siteler Family Health Center. Participant consents were received.

\section{Study Inclusion Criteria:}

Willingness to participate in the study.

Age $>18$ years.

Literacy.

No diagnosed psychiatric disorder.

\section{Questionnaire forms used}

A questionnaire form examining the patients' sociodemographic characteristics, Newest Vital Sign (NVS) survey to measure the health literacy level, and Turkish and English versions of the Public Health Literacy Knowledge Scale were used in this study.

\section{Questionnaire form on socio-demographic information:}

Gender, age, marital status, height, weight, body mass index, presence of smoking and alcohol usage and its amount if present were questioned. Moreover, 
profession, educational status, income level and chronic diseases were questioned.

Among the anthropometric measurements, height and weight were measured using standard measuring tools. The individuals were asked to take off their shoes during height measurements. It was also ensured that the clothes and items that would cause weight on the patients were removed during weight measurement.

Body mass index (BMI) value was calculated by dividing the patient's weight by the square of his/her height (weight/height ${ }^{2}-\mathrm{kg} / \mathrm{m}^{2}$ ).

\section{Newest Vital Sign Assessment Tool (NVS):}

This tool was developed by Weiss et al. (2005). It comprises 6 questions concerning a nutrition label from a container of ice cream. It takes about 3-6 minutes to administer the NVS. The first four questions require calculation and the last two questions do not require computational skills. The NVS test examines both reading and interpreting the text. It measures literacy, calculation and comprehension skills (8).

Each correct answer of the participant is calculated as 1 point and his/her health literacy level is determined according to his/her total score.

1. Total score $0-1$ : High likelihood ( $50 \%$ or more) of limited health literacy

2. Total score 2-3: Possibility of limited health literacy

3. Total score 4-6: Adequate health literacy.

\section{Public Health Literacy Knowledge Scale}

This is a scale consisting of 17 items on basic topics related to public health (2). Each correct answer is scored 1 point and assessment is made over a total score of 17.

\section{Statistical analysis}

Scale reliability was analyzed with a test-retest method and internal consistency was analyzed with Cronbach alpha reliability coefficient. Test-retest correlation was analyzed with Spearman (rs) correlation coefficient. In the criteria validation analysis of the scale, the relationship between the scores of the PHL scale and the scores of the NVS scale was examined with Spearman correlation coefficient (rs). Construct validity was examined using exploratory factor analysis (EFA) and confirmatory factor analysis (CFA). With EFA, it was aimed to explore the factor structure of the scale within the study population. With CFA, conformity of the scale with the scale model obtained as a result of the EFA was researched and the ability of the scale to identify different constructs was examined. Ability of the PHL scale to identify different expected constructs was evaluated with statistical analysis in terms of sociodemographic characteristics. In statistical analysis, Kruskal Wallis Test and Mann-Whitney U Test were used to analyze the differences among groups. As descriptive statistics, mean and standard deviation or median (minimum-maximum) values are given for continuous variables. Categorical variables are shown as $\mathrm{n}$ and percentage values. Significance level is assumed as $a=0.05$. Bonferroni correction ( $a^{*}$ ) was made for tests of significance in multiple comparisons. SPSS 21 (IBM Corp. Released 2012. IBM SPSS Statistics for Windows, Version 21.0. Armonk, NY: IBM Corp), Factor v.10.8.04 and Amos (Arbuckle, J. L. (2014). Amos (Version 23.0) [Computer Program]. Chicago: IBM SPSS.) were used in statistical analysis.

\section{Results}

Socio-demographic status of the participants is given in Table1. $30 \%$ of the participants were university graduates, $26.8 \%$ were high school graduates and $42.4 \%$ were primary education graduates. 
Table1. Socio-demographic characteristics of the participants

\begin{tabular}{|c|c|}
\hline & $\mathrm{n}=\mathbf{2 5 0}$ \\
\hline \multicolumn{2}{|l|}{ Age (year) } \\
\hline Between 20-24 & $48(19.20 \%)$ \\
\hline Between 25-29 & $61(64.40 \%)$ \\
\hline Between 30-34 & $55(22 \%)$ \\
\hline Between 35-39 & $49(19.60 \%)$ \\
\hline Between 40-44 & $37(14.80 \%)$ \\
\hline \multicolumn{2}{|l|}{ Gender } \\
\hline Male & $125(50 \%)$ \\
\hline Female & $125(50 \%)$ \\
\hline Height (cm) & $167 \pm 8.95(125: 190)$ \\
\hline Weight (kg) & $75.69 \pm 15(40: 160)$ \\
\hline BMI $\left(\mathrm{kg} / \mathrm{m}^{2}\right)$ & $26.95 \pm 5.26(17.01: 51.20)$ \\
\hline \multicolumn{2}{|l|}{ Marital Status } \\
\hline Married & $201(80.40 \%)$ \\
\hline Single & $31(12.40 \%)$ \\
\hline Separated/Divorced & $14(5.60 \%)$ \\
\hline Widow & $4(1.60 \%)$ \\
\hline Smoking & $70(28 \%)$ \\
\hline Cigarettes (numbers in a day) & $15.47 \pm 9.70(1: 50)$ \\
\hline Alcohol Users & $14(5.60 \%)$ \\
\hline \multicolumn{2}{|l|}{ Profession } \\
\hline Officer & $65(26)$ \\
\hline Housewife & $58(23.30)$ \\
\hline Farmer & $40(16)$ \\
\hline Craft & $34(13.60)$ \\
\hline Worker & $24(9.60)$ \\
\hline Retired & $23(9.20)$ \\
\hline Student & $6(2.40)$ \\
\hline \multicolumn{2}{|l|}{ Education } \\
\hline Literate & $2(0.80 \%)$ \\
\hline
\end{tabular}


Table1. Socio-demographic characteristics of the participants (Continued)

\begin{tabular}{|l|c|}
\hline Primary school & $70(28 \%)$ \\
\hline Secondary school & $36(14.40 \%)$ \\
\hline High school & $27(26.80 \%)$ \\
\hline Associate degree & $45(18 \%)$ \\
\hline Undergraduate & $3(1.20 \%)$ \\
\hline Postgraduate & $4(1.60 \%)$ \\
\hline Income & $157(63.10 \%)$ \\
\hline Bad & $84(33.70 \%)$ \\
\hline Medium & $4(1.60 \%)$ \\
\hline Good & \\
\hline Very good & \\
\hline
\end{tabular}

Data expressed as mean \pm standard deviation (minimum: maximum), median (minimum: maximum) and $n(\%)$.

Chronic diseases of the participants are shown in

Table2. $12.8 \%$ of the participants had hypertension,

Table2. Chronic Disease Distribution
$8.8 \%$ had diabetes mellitus, $6 \%$ had cardiovascular disease and $3.6 \%$ had asthma.

\begin{tabular}{|l|l|}
\hline & $\mathbf{n = 2 5 0}$ \\
\hline Chronic Disease & $83(33.20 \%)$ \\
\hline Hypertension & $32(12.80 \%)$ \\
\hline Diabetes Mellitus & $22(8.80 \%)$ \\
\hline Cardiovascular disease & $15(6 \%)$ \\
\hline Asthma & $9(3.60 \%)$ \\
\hline Rheumatologic disease & $8(3.20 \%)$ \\
\hline Hyperlipidemia & $7(2.80 \%)$ \\
\hline Nephropathy & $5(2 \%)$ \\
\hline Hypothyroid & $4(1.60 \%)$ \\
\hline Chronic Obstructive Pulmonary Disease & $4(1.60 \%)$ \\
\hline Others & $18(7.20 \%)$ \\
\hline
\end{tabular}

Data given as median (minimum: maximum) and $n$ (\%). 


\section{Validity analysis}

\section{Language Equivalence Studies of the Scale}

We contacted Andrew Pleasant, developer of the 'Public Health Literacy Knowledge Scale', for the Turkish adaptation of the scale and we obtained the necessary permission. In scale adaptation studies from foreign languages, conformity of the expressions with the target language and culture is of great importance. Translation of the form from English to Turkish was accomplished in two stages. In the first step, the scale was translated to Turkish by two experts; a native Turkish linguist and a professional in the field, by considering the scale items independently from each other. It was then examined by the researchers in terms of the most appropriate translation, content integrity and conceptual equivalence for each item. The scale that was translated to Turkish was retranslated to English with a back-translation method. It was then compared with its original form and translations considered as the best expressing ones for the questionnaire items were adapted. The finalized Turkish questionnaire form was submitted to 40 undergraduate students in the Departments of English Teaching and English Language and Literature. According to the results obtained, a high positive relationship was found between Turkish and English versions of the scale $\left(r_{s}=0.78, p<0.001\right)$. In this context, it was assessed that Turkish and English versions of the scale are equivalent and thus we decided to continue to validity reliability studies.

\section{Criterion Validity}

The NVS scale developed by Weiss et al. was used to determine the criterion validity of the scales. A significant relationship in the same direction was detected $\left(r_{s}=0.68 ; p<0.001\right)$ between the total scores of the PHL scale and the NVS scale and it was assumed that the PHL scale met the criterion validity.

\section{Construct Validity}

Exploratory factor analysis (EFA) and confirmatory factor analysis (CFA) were applied to determine the construct validity of the PHL scale. In the exploratory factor analysis (EFA), while determining the scale items, it was taken into consideration that the eigen value of factors was at least 1 (9), loading value of the items was at least $0.30(10,11)$, items were in a single factor and there was at least 0.10 factor loading difference between items in two factors (12). Before the exploratory factor analysis, Kaiser Meyer-Olkin (KMO) test for sampling adequacy and Bartlett's test of sphericity were applied to assess whether the sampling was adequate and factor correlation matrix was convenient. The KMO value was 0.61 ; Bartlett test result was $X^{2}=381.60$ and it was assumed to be statistically significant $(p<0.001)$. According to Tavşancıl, factor analysis can be applied in case the KMO test result is over 0.50 . Also, the significance of the Bartlett test is an indicator of the adequacy of the scale item correlation matrix for factor analysis (13). According to the result obtained in this study, 0.61 KMO score showed that the sampling was mediocre for factor analysis and the significance of the Bartlett test indicated that the item correlation matrix was adequate. As the responses given to the items on the PHL scale are bivalent (true/false), Polychoric correlation matrix was used in factor analysis. Parallel analysis was used to determine the number of factors in exploratory factor analysis (14). Principal Components Analysis was used as the factor extraction method, and Varimax rotation technique, which is one of the most frequently used orthogonal rotation techniques, was used to provide independence during analysis and explicity in interpretation. In the exploratory factor analysis performed, it was detected that eigen values of 17 items were over 1 and they were divided into seven factors, explaining $56.60 \%$ of total variance. Total variance explanation percentages 
for the factors were calculated as: $10.99 \%$ for the first factor, $8.88 \%$ for the second factor, $8.48 \%$ for the third factor, $7.98 \%$ for the fourth factor, $6.95 \%$ for the fifth factor, $6.51 \%$ for the sixth factor and $6.09 \%$ for the seventh factor. While it is expected that at least $30 \%$ of the total variance is explained in single factor scales, in multi-factor structures this figure is expected to be much higher (12). Nevertheless, although there is not a precise limit in the literature for loading values explaining the item relationships with factors, Büyüköztürk indicates that the lowest acceptable factor loading value is 0.30 and factor loading values higher than 0.45 is a good measure for selection (12). In our study, one item (question number 5) was eliminated because its factor loading value was lower than 0.30 . According to another criterion, items should have a high loading value for a single factor and low loading value for other factors, but in case this criterion is fulfilled, independent constructs are likely to be explored. Büyüköztürk suggests that the difference between two high loading values should be at least 0.10 (12). 2 items (question 8 and question 15) that did not meet this criterion were removed from the study and the analysis continued with 14 items.
As a result of second EFA application, the KMO value was 0.60; Bartlett test result was $X^{2}=299.40$ and it was considered statistically significant $(p<0.001)$. The significance of the Bartlett test shows that the correlation matrix of the items was adequate. As the responses given to the items of the PHL scale are bivalent (true/false), Polychoric correlation matrix was used in factor analysis. Parallel analysis was used to determine the number of factors in exploratory factor analysis (14). Varimax rotation technique, which is one of the most frequently used orthogonal rotation techniques, was used to provide independence during analysis and explicity in interpretation during factor analysis. In the exploratory factor analysis performed, it was detected that 14 items were divided into 5 factors of which eigen values were over 1 , explaining $56.10 \%$ of total variance. Besides this, question number 14 was eliminated because its factor loading value was lower than 0.30 . In the third performing of EFA, question number 1 was eliminated as well because its factor loading value was lower than 0.30 and according to final analysis results, it was observed that eigenvalues of the remaining 12 items were over 1 and they were grouped under 3 factors explaining $47.36 \%$ of the total variance (Table-3).

Table3. Item Factor Loadings of the Public Health Literacy Knowledge Scale

\begin{tabular}{|l|l|l|l|l|l|l|}
\hline \multirow{2}{*}{ Factor 1 } & Question No & $\mathbf{9}$ & $\mathbf{1 0}$ & $\mathbf{1 1}$ & $\mathbf{1 2}$ & \\
\hline & Factor Loading & 0.83 & 0.66 & 0.67 & 0.46 & \\
\hline Eigen value & 2.29 & & & & & \\
\hline Variance\% & $19.12 \%$ & & & & & \\
\hline \multirow{2}{*}{ Factor 2 } & Question No & $\mathbf{2}$ & $\mathbf{6}$ & $\mathbf{7}$ & $\mathbf{1 3}$ & $\mathbf{1 7}$ \\
\hline & Factor Loading & 0.75 & 0.46 & 0.57 & 0.51 & 0.91 \\
\hline Eigen value & 1.87 & & & & & \\
\hline Variance\% & $15.56 \%$ & & & & & \\
\hline \multirow{2}{*}{ Factor 3 } & Question No & $\mathbf{3}$ & $\mathbf{4}$ & $\mathbf{1 6}$ & & \\
\hline Eigen value & Factor Loading & 0.65 & -0.36 & 0.89 & & \\
\hline Variance\% & 1.52 & & & & & \\
\hline & $12.68 \%$ & & & & & \\
& $\begin{array}{l}\text { Total Explained Variance: } 47.36 \% \\
\text { Kaiser-Meyer-Olkin (KMO) test: } 0.60 \\
\text { Bartlett Statistics: } \chi^{2} \text { (66) }=262.30 ; \mathbf{p}<\mathbf{0 . 0 0 1}\end{array}$ & & & \\
\hline
\end{tabular}




\section{Confirmatory Factor Analysis (CFA)}

In the construct validity analysis, confirmatory factor analysis was performed to evaluate the adequacy of the PHL scale 3-factor model and goodness of fit criteria were calculated. 12 items and 3-factor structure created with EFA and existing in the Turkish version of the PHL scale were tested with Confirmatory Factor Analysis (CFA). When goodness of fit criteria of confirmatory factor analysis results was considered, it was seen that it was supporting the 3-factor structure obtained as a result of EFA. In this study, goodness of fit criteria was detected as: $x^{2}$ test statistics 70.60, $u$ value 52, $X^{2}$ / U value 1.36, "Root Mean Square Error Approximation (RMSEA)" value 0.04, Tucker-Lewis Index (TLI) 0.88 and "Comparative Fit Index" (CFI) 0.91 (Table-4).

Table4. Model fit criteria for 3-factor model of the Public Health Literacy Knowledge Scale

\begin{tabular}{|l|l|}
\hline Criteria & Model \\
\hline$\chi^{2}$ & $70.60_{(52)} ; \mathrm{p}=0.044$ \\
\hline$\chi^{2} / v$ & 1.36 \\
\hline RMSEA & $0.04, \% 90 \mathrm{GA}: 0.01-0.06, \mathrm{p}=0.814$ \\
\hline TLI & 0.88 \\
\hline CFI & 0.91 \\
\hline
\end{tabular}

CI: Confidence Interval, u: Degree of freedom, RMSEA: Root mean square error approximation,

TLI: Tucker-Lewis Index, CFI: Comparative Fit Index

\section{Reliability analysis}

When scale reliability was analyzed in terms of internal consistency, the Cronbach alpha coefficient of the PHL scale was $a=0.58$. Internal consistency of the PHL form suggested in our study was also assessed with Cronbach alpha coefficient and calculated as $\mathrm{a}=0.53$.

In the reliability analysis with a test-retest method, the PHL scale was re-applied to a group of 40 individuals two to three weeks after the first application and the test-retest correlation was $r_{s}=0.93(p<0.001)$.

\section{Discussion}

In the Language Equivalence Study of the scale, a high positive relationship was detected between the Turkish and English forms. A significant relationship was found in the same direction between the total scores of the Public Health Literacy Knowledge Scale and the Newest Vital Sign scale and it was predicted that the
Public Health Literacy Knowledge scale fulfilled the criteria validity. When scale reliability was examined in terms of internal consistency, the Cronbach alpha coefficient of the Public Health Literacy Knowledge scale was $a=0.58$. Considering this Cronbach alpha coefficient, this scale has a weak level as a measuring tool in terms of internal consistency (15). Internal consistency of the PHL form suggested in our study was also assessed with Cronbach alpha coefficient and calculated as $a=0.53$, showing that this version of 12 questions has a weak level as a measuring tool (15). In the reliability analysis with a test-retest method, the PHL scale was re-applied to a group of 40 individuals two to three weeks after the first application and the test-retest correlation was $r_{s}=0.93(p<0.001)$.

In scale adaptation studies from foreign languages, conformity of the expressions to the target language and culture is of great importance. Culture is a dynamic structure and may vary among societies. For this reason, this dynamic structure must be considered 
during scale adaptation studies (16). The Turkish translation of the 'Public Health Literacy Knowledge Scale', which was published only in English, was done in two stages. According to the results obtained, a high positive relationship was found between Turkish and English versions of the scale $\left(r_{s}=0.78, p<0.001\right)$. In this context, it was assessed that Turkish and English versions of the scale are equivalent. During the interviews, we faced difficulty in asking and getting responses from females over a certain age for the question 'Using condoms when having sex can prevent the spread of AIDS'. Thus, the rate of individuals who did not answer the related question was $7.6 \%$. The same rate appeared in the response for the question 'The father's genes determine the baby's gender'. The rate of wrong answers to the question about genes was also high.

'Validity is a concept about what the test measures and how accurately it measures it and whether the test really measures the variable that the researcher thinks it measures. There are several criteria to test the validity. These are content validity, criterionrelation validity and construct validity' (17). In this study, we used criterion validity and construct validity to test the scale validity. The NVS scale (8) developed by Weiss et al. (2005) was taken as a criterion to determine the criterion validity of the scale. A significant relationship in the same direction was found between the total scores of the PHL scale and the NVS scale and it was assumed that the PHL scale met the criterion validity. Criterion validity of NVS: ( $r=$ $0.59, P<.001)(8)$.

'Time invariance (test-retest), internal consistency (KuderRichardson-20, Cronbach alpha coefficient), parallel (equivalent) form, split-half test, item analysis methods are used for reliability' (17). Test-retest determines the stability of the test and measurements like Kuder-Richardson and Cronbach alpha determine the homogeneity of the test (18). We applied Cronbach alpha and the test-retest method. 'Alpha was developed by Lee Cronbach in 1951 to provide a measurement of a test's or scale's internal consistency; it is expressed as a number between 0 and 1 . Internal consistency defines to what extent all elements in a test measure the same concept or structure and thus whether the elements within the test are associated with each other' (19). When scale reliability was examined in terms of internal consistency, the Cronbach alpha coefficient of the Public Health Literacy Knowledge scale was $a=0.58$. Cronbach alpha coefficient: $\quad \geq 0.9$ excellent, $0.7 \leq a<0.9$ good, $0.6 \leq \mathrm{a}<0.7$ acceptable, $0.5 \leq \mathrm{a}<0.6$ poor, $\mathrm{a}<0.5$ unacceptable (15). Considering this Cronbach alpha coefficient, it has been observed that this scale is a weak measuring tool in terms of internal consistency (15). Internal consistency of the PHL form suggested in our study was also assessed with Cronbach alpha coefficient and calculated as $\mathrm{a}=0.53$ and it has been also observed that this version of 12 questions is a weak measuring tool. The Cronbach alpha value for the 'Public Health Literacy Knowledge Scale' has been indicated as 0.7973 for the total data of all countries (2). 'The calculated low a value may be due to the low number of items in the scale' (15). According to Tavakol 'The number of test items, item interrelatedness and dimensionality affect the value of alpha. A low value of alpha could be due to a low number of questions, poor inter-relatedness between items or heterogeneous constructs. A high alpha coefficient does not always mean a high degree of internal consistency. This is because alpha is also affected by the length of the test. If the test length is too short, the value of alpha is reduced.' (19). Pleasant indicates that he has turned to a body of information called 'Facts for Life' to eliminate concerns such as content validity in the 'Public Health Literacy Knowledge Scale' (2). 
$75 \%$ of the responses given to Pleasant's 'Public Health Literacy Knowledge Scale' in Mexico, China, Ghana and India were correct on average. The poorest overall performance was in response to 'Coughs and colds only get better with medicine', where less than half $(41 \%)$ of the participants responded correctly that the statement is false. Four of the statements received a correct response at a rate of $90 \%$ - those relating to 'For a healthy pregnancy and birth, all pregnant women should visit a health worker before the baby is born; Children learn a lot by playing; If a child is breathing rapidly or has difficulty breathing, the child should be taken immediately to a health-care provider; Many diseases can be prevented by washing hands before touching food (2). When responses given to the Turkish PHL scale, which was conducted with 250 individuals proportionally equal in terms of the unit population pyramid and who had visited the family health department, were considered, $84.4 \%$ of them were correct on average. The poorest performance was in response to 'The father's genes determine the baby's gender', where $63.6 \%$ of the participants responded correctly. The best performance was in response to 'If a child is breathing rapidly or has difficulty breathing, the child should be taken immediately to a health-care provider', where $99.2 \%$ of the participants responded correctly. More than $98 \%$ of the participants responded correctly to the six following questions; 'For a healthy pregnancy and birth, all pregnant women should visit a health worker before the baby is born; Children who are vaccinated are protected from dangerous diseases; Children learn a lot by playing; If a child is breathing rapidly or has difficulty breathing, the child should be taken immediately to a health-care provider; Many diseases can be prevented by washing hands before touching food; Cigarette smoking causes lung cancer'.

There are no questions in the 'Public Health Literacy Knowledge Scale' on the topics from 'Facts for Life':
Timing of births, Breastfeeding, Diarrhea, Child protection, Emergency preparedness and response. Questions on the scale: 'Exercise helps prevent heart disease; The father's genes determine the baby's gender; Antibiotics kill viruses as well as bacteria; All bacteria are harmful to humans' did not have an exact equivalent in the 'Facts for Life'.

As a conclusion, the Turkish validity of the PHL scale was achieved in this study. Internal consistency of the scale can be assessed to be weak but its reliability is excellent. The relationship between the PHL scale and healthcare services, protection and promotion of health topics associated with health literacy, as for the equivalent NVS scale, should be analyzed in further studies.

\section{CONFLICT OF INTEREST}

The authors declare that they have no conflict of intrest.

\section{References}

1. https://www.unicef.org/publications/files/Facts $f$ or Life EN 010810.pdf Access Date: 06.02.2020.

2. Pleasant A, Kuruvilla SS: A tale of two health literacies: public health and clinical approaches to health literacy. Health Promot Int. 2008; 23 (2): 152-159.

3. Waltz CF, Strcikland OL, Lenz ER. Measurement in Nursing and Health Research. New York: Springer Publishing Company; 2010. p.176-8.

4. Kline RB. Principles and Practice of Structural Equation Modeling. New York: Guilford Press; 2005.p.154-186

5. Andrew DPS, Pedersen PM, McEvoy CD. Research Methods in Sport Management. Champaign: Human Kinetics; 2011. p.203-7.

6. MacCallum RC, Widaman KF, Zhang S, Hong, S. Sample size in factor analysis. Psychological Methods. 1999; 4(1): 84-99. 
7. Erkuş A. Psikolojide ölçme ve ölçek geliştirme-I: Temel kavramlar ve işlemler (2. Baskı). Ankara: Pegem Akademi, 2014.

8. Weiss $B D$, Mays MZ, Martz $W$, Castro KM, DeWalt DA, Pignone MP,et al: Quick Assessment of Literacy in Primary Care: The Newest Vital Sign. The Annals of Family Medicine 2005; 3(6): 51422.

9. Shevlin ME, Lewis CA. The revised social anxiety scale: exploratory and confirmatory factor analysis. The Journal of Social Psychology. 1999; 139: $250-252$

10. Martin CR, Newell RJ. Factor structure of the Hospital Anxiety and Depression Scale in individuals with facial disfigurement. Psychology, Health \& Medicine. 2004; 9: 327-336

11. Schriesheim CA, Eisenbach RJ. An exploratory and confirmatory factor-analytic investigation of item wording effects on the obtained factor structures of survey questionnaire measures. Journal of Manag. 1995; 21: 1177-1193

12. Büyüköztürk Ş. Sosyal bilimler için veri analizi el kitabı. Pegem Atıf İndeksi:2017; 1-213
13. Tavşancıl E. Tutumların ölçülmesi ve SPSS ile veri analizi. Ankara: Nobel Yayincilik; 2002.

14. Timmerman ME, Lorenzo-Seva U. Dimensionality assessment of ordered polytomous items with parallel analysis. Psychological methods. 2011; 16: 209.

15. Kiliç S. Cronbach's alpha reliability coefficient. Journal of Mood Disorders. 2016; 6: 47.

16. Akbaş, G. ve L. Korkmaz. Ölçek uyarlaması (Adaptasyon)." Türk Psikoloji Bülteni. 2007; 13 (40): 15-16.

17. Sezer A, Kadıoğlu H.Yetişkin Sağlık Okuryazarlığı Ölçeğinin Geliştirilmesi. Anadolu Hemşirelik ve Sağlık Bilimleri Dergisi. 2014; 17: 3

18. Aktürk Z, Acemoğlu H. Tıbbi araştırmalarda güvenilirlik ve geçerlilik. Dicle Tıp Derg. 2012; 39 (2): 316-319.

19. Tavakol M, Dennick R. Making sense of Cronbach's alpha. International Journal of Medical Education. 2011; 2: 53-5. 